Research Article

\title{
A Pre-experimental Study to assess the Effectiveness of National Guidelines for Diagnosis and Management of Gestational Diabetes Mellitus (GDM) developed by Ministry of Health and Family Welfare (MoHFW) in terms of Knowledge among Nurse Educators in selected Colleges of Nursing, New Delhi, India
}

\author{
Deepti Kukreti', Urmila D Bhardwaj', Merlin Mary James ${ }^{3}$, Jahanara Rahman ${ }^{4}$
}

${ }^{1}$ M.Sc. Nursing (Obstetrics and Gynaecological Nursing) Student, ${ }^{2}$ Principal, ${ }^{3}$ Ex-Faculty, ${ }^{4}$ Assistant Professor, Rufaida College of Nursing, Jamia Hamdard, New Delhi, India.

DOI: https://doi.org/10.24321/2455.9318.202001

\section{I $\quad \mathbf{N} \quad \mathbf{F} \quad \mathbf{O}$}

Corresponding Author:

Deepti Kukreti, Rufaida College of Nursing, Jamia Hamdard, New Delhi, India.

E-mail Id:

deepkukreti22@gmail.com

Orcid Id:

https://orcid.org/0000-0003-4334-4834

How to cite this article:

Kukreti D, Bhardwaj UD, James MM, A Rahman J. Pre-experimental Study to assess the Effectiveness of National Guidelines for Diagnosis and Management of Gestational Diabetes Mellitus (GDM) developed by Ministry of Health and Family Welfare (MoHFW) in terms of Knowledge among Nurse Educators in selected Colleges of Nursing, New Delhi, India. Int J Nurs Midwif Res 2020; 7(1): 2-7.

Date of Submission: 2020-05-01

Date of Acceptance: 2020-06-01

\section{$\begin{array}{llllllll}\text { A } & \text { B } & \mathbf{S} & \mathbf{T} & \mathbf{R} & \mathbf{A} & \mathbf{C} & \mathbf{T}\end{array}$}

Introduction: Gestational Diabetes Mellitus (GDM) is an important public health problem in India as a factor influencing safe motherhood and as a precursor of Type 2 Diabetes Mellitus. Considering the high prevalence (10\%-14\%) of GDM in India, the awareness regarding the National Guidelines for Diagnosis and Management of GDM among nurse educators is of paramount importance.

Objectives: The study was aimed to assess the effectiveness of National guidelines for diagnosis and management of GDM developed by MoHFW in terms of knowledge among nurse educators.

Materials and Methods: A quantitative approach with pre-experimental, one group pre-test post-test design was used among 30 nurse educators teaching midwifery-gynaecological nursing and community health nursing were selected using purposive sampling technique from four nursing colleges of New Delhi through a structured knowledge questionnaire. Data were analysed using descriptive and inferential statistics.

Result: Findings revealed that before administering the guidelines, 26 (86\%) nurse educators had average, 2 (7\%) had below and 2 (7\%) had above average knowledge regarding National guidelines and post - test knowledge scores revealed that 22 (73\%) of nurse educators had average knowledge, whereas rest $8(27 \%)$ showed improvement in their knowledge by scoring above average marks. The ' $t$ ' value computed was 17.06 , which was statistically significant at 0.05 level of significance.

Conclusion: The present study revealed that most of the nurse educators had below average knowledge regarding National Guidelines because they were either not updated with the recent guidelines. Thus dissemination of guidelines among nurse educators was an effective study material for them and also for imparting knowledge to nursing students.

Keywords: GDM, Knowledge, Nurse Educators 


\section{Introduction}

Pregnancy is a unique, exciting and often joyous time in a woman's life, as it highlights the woman's amazing creative and nurturing powers while providing a bridge to the future and is a period from conception to birth. After the egg is fertilized by a sperm and then implanted in the lining of the uterus, it develops into the placenta and embryo, and later into a foetus. It is true that pregnancy is a joyful event however, in some instances it may be accompanied by health problems like gestational hypertension, Gestational Diabetes Mellitus (GDM), pre-eclampsia, pre-term labour, miscarriage, still birth and other infections. Among all, GDM is one of the common complications of pregnancy. ${ }^{1}$

Gestational Diabetes Mellitus (GDM) is defined as impaired glucose tolerance (IGT) with onset during pregnancy. It usually refers to diabetes in a pregnant woman who did not have diabetes before becoming pregnant. Worldwide, one in 10 pregnancies is associated with diabetes, $90 \%$ of which are GDM. ${ }^{2}$

In India, being one of the most populous countries globally, the rates of GDM are estimated to be $10-14.3 \%$ which is much higher than the western countries. As of 2010, there were an estimated 22 million women with diabetes between the ages of 20 and 39 \& an additional 54 million women in this age group with Impaired Glucose Tolerance (IGT) or pre-diabetes with the potential to develop GDM if they become pregnant. The incidence of GDM is expected to increase to $20 \%$ i.e. one in every 5 pregnant women is likely to have GDM. ${ }^{2}$

GDM is one of the important public health problems in India as it is a factor which influences safe motherhood and also is a precursor of Type 2 Diabetes Mellitus. This calls for an immediate attention to be adequately and promptly being recognized during pregnancy as it is a major contributor to the spike in maternal and foetal mortality and morbidity. There are several risks and complications associated with GDM, macrosomia, hypoglycaemia, jaundice, respiratory distress syndrome, polycythaemia and hypocalcaemia in infants. ${ }^{3}$

From the perspective of chronic, non-communicable diseases, many women who have GDM, their off springs are at a higher risk of developing type- 2 diabetes mellitus in later life. Thus, appropriate management of GDM will go a long way in reducing the number of people that could be affected by Type 2 diabetes in future years. It is managed initially with medical nutrition therapy and physical exercise and if it is not controlled with MNT (lifestyle changes), Metformin or Insulin Therapy is added to the MNT. ${ }^{2}$

A study was conducted by Patel $S$ and Vyas $S^{1}$ related to evaluation of training program about awareness of GDM among health care workers of Ahmedabad Municipal
Corporation. Total of 400 health care providers of Ahmedabad Municipal Corporation who attended the GDM Training session were included in study were Accredited Social Health Activists (ASHA), Auxiliary Nurse Midwife etc. A predesigned and pretested proforma was used for pre and post training assessment of the knowledge of the participants. The study results revealed that prior to training 162 (40.5\%) participants could correctly tell about GDM which increased to $50 \%$ after training. Before training $21.25 \%$ participants could tell all effects of GDM on mother which increased to $55 \%$ after training. Knowledge of effect on new-born increased from $14 \%$ to $52.5 \%$. There was significant increase in knowledge of participants in aspects of GDM. Knowledge about GDM is poor amongst health care providers and hence calls for a need for training. ${ }^{1}$

GDM occurs when a woman's pancreatic function is not sufficient to overcome the diabetogenic environment of pregnancy and causes high blood glucose levels due to the body's extra demand for insulin. A variety of factors like age, diet, obesity, ethnicity, family history, history of GDM in previous pregnancy, macrosomia essential hypertension or pregnancy-related hypertension, history of spontaneous abortions, and unexplained stillbirths cause an increased risk of glucose intolerance in pregnant women. ${ }^{1}$

Nursing educators have a colossal role in honing the skills of student nurses in providing quality care to pregnant women. If the nursing educators provide education regarding the timely screening for GDM and its appropriate management to the student nurses, it would enable them to practice and manage effectively the cases of gestational diabetes mellitus, thereby yielding tangible results. It is of paramount importance that nursing educators to be updated with the National guidelines on Gestational Diabetes Mellitus by attending regular trainings.

\section{Objectives}

The objective of the study were:

- To assess the pre-test knowledge scores of nurse educators regarding National Guidelines for diagnosis and management of GDM.

- To assess the post-test knowledge scores of nurse educators after administration of National Guidelines for diagnosis and management of GDM.

- To find out association between the knowledge of nurse educators regarding National Guidelines for diagnosis and management of GDM with their selected demographic variables i.e. professional qualification, designation, experience and whether attended program on GDM.

\section{Research Hypothesis}

There will be a significant difference between the mean knowledge scores of nurse educators before and after the 
administration of National Guidelines for diagnosis and management of GDM as assessed by structured knowledge questionnaire at 0.05 level of significance.

\section{Materials and Methods}

A quantitative research approach was used in this study to assess the effectiveness of National Guidelines on diagnosis and management of GDM in terms of knowledge among nurse educators in selected nursing colleges of New Delhi from $19^{\text {th }}$ October to $4^{\text {th }}$ November 2019. A pre-experimental one group pre-test post-test group research design was used. A purposive sampling technique was used to select 30 nurse educators teaching midwifery - gynaecological nursing and community health nursing in selected colleges of nursing, who were available during data collection period and are willing to participate in the study were included. The research instrument used was structured knowledge questionnaire on national guidelines for diagnosis and management of GDM developed by MoHFW, which was validated by 9 experts from the fields of Midwifery and Community health nursing. The reliability of the tool was established by using Kuder Richardson 20 Formula with value of ' $r$ ' as 0.82 which proved the tool to be reliable.

The formal permission for conducting research was obtained from four different colleges of nursing in Delhi. Ethical approval was sought from the Institutional Ethical Committee of Jamia Hamdard. Pilot study was conducted on 7 nurse educators from a nursing college in Delhi. Participants were given full explanation regarding the objectives of the study and written consent was taken and confidentiality was assured to the subjects.

The structured knowledge questionnaire comprised of 3 sections, Section 1: Demographic Profile of Nurse Educators, Section 2: Structured Knowledge Questionnaire based on National Guidelines for Diagnosis and Management of Gestational Diabetes Mellitus and Section 3: Case Scenario in form of questionnaire based on National Guidelines for Diagnosis and Management of Gestational Diabetes Mellitus was included. There were $59 \mathrm{MCQ}$ items in 3 sections with each question comprising of three distracters and one correct option. A score of 'one' was assigned to each correct option selected by the participants. The overall score was used to judge participants knowledge level and was categorized in ranges as below average knowledge (019), average knowledge (20-39), above average knowledge (40-59).

Pre-test was conducted on the same day before dissemination of hard copies of National Guidelines, followed by post-test after a gap of 7 days by using same tool among the participants. The analysis of demographic data was done in terms of frequency and percentage. The knowledge of the nurse educators before and after dissemination of National Guidelines was analysed in terms of frequency, mean, median, percentage and standard deviation as well as paired t-test was calculated.

\section{Result}

The findings of the present study were divided into the following sections:

\section{Section I: Findings related to Demographic Profile of Nurse Educators}

Frequency and percentage of the nurse educators were computed by their age, professional qualification designation, years of experience and attended programme on GDM, (table 1).

Table I.Frequency and percentage distribution of demographic profile of nurse educators

$(n=30)$

\begin{tabular}{|c|c|c|c|}
\hline $\begin{array}{l}\text { S. } \\
\text { No. }\end{array}$ & $\begin{array}{c}\text { Sample } \\
\text { characteristics }\end{array}$ & $\begin{array}{c}\text { Frequency } \\
\text { (f) }\end{array}$ & $\begin{array}{c}\text { Percentage } \\
(\%)\end{array}$ \\
\hline 1. & \multicolumn{3}{|c|}{ Age (in years) } \\
\hline & $21-30$ & 15 & 50 \\
\hline & $31-40$ & 8 & 27 \\
\hline & $41-50$ & 3 & 10 \\
\hline & Above 50 & 4 & 13 \\
\hline 2. & \multicolumn{3}{|c|}{ Professional qualification } \\
\hline & B.Sc. Nursing & 1 & 3 \\
\hline & M.Sc. Nursing & 27 & 90 \\
\hline & Ph.D. Nursing & 2 & 7 \\
\hline 3. & \multicolumn{3}{|c|}{ Designation } \\
\hline & Tutor & 20 & 67 \\
\hline & Senior Tutor & 1 & 3 \\
\hline & $\begin{array}{c}\text { Lecturer/ Assistant } \\
\text { Professor }\end{array}$ & 5 & 17 \\
\hline & Associate Professor & 2 & 7 \\
\hline & Professor & 2 & 7 \\
\hline 4. & \multicolumn{3}{|c|}{ Years of experience } \\
\hline & $1-5$ years & 16 & 53 \\
\hline & $6-10$ years & 6 & 20 \\
\hline & $11-15$ years & 4 & 13 \\
\hline & Above 15 years & 4 & 13 \\
\hline 5. & \multicolumn{3}{|c|}{ Attended programme on GDM } \\
\hline & Yes & 5 & 17 \\
\hline & No & 25 & 83 \\
\hline
\end{tabular}

Section 2: Findings related to Level of Knowledge of Nurse Educators Before and After Administration of National Guidelines

The knowledge scores of the nurse educators were 
categorized as below average knowledge, average knowledge and above average knowledge (Figure 1).

The data presented in Table 2 and Figure 1, shows that before administering the guidelines, most of the nursing educators 26 (86\%) had average knowledge whereas only $2(7 \%)$ had below and above average knowledge regarding the National guidelines, whereas after administration of the national guidelines for diagnosis and management of GDM, 22 (73\%) nurse educators had above average marks, whereas $8(27 \%)$ of nurse educators, showing a marked improvement in their knowledge scores.

Section 3: Findings related to Area-wise Modified Mean Percentage and Modified Mean Percentage Gain in Post-test knowledge Score of Nurse Educators regarding National GuidelinesFigure 2.Compound bar diagram showing area-wise modified mean percentage and modified mean percentage gain in post-test knowledge score of nurse educators

The data presented in Figure 2, shows that there is gain in post-test modified mean percentage knowledge scores in all the content areas, indicating the effectiveness of National guidelines for diagnosis and management of GDM developed by MoHFW.
Section 4: Findings related to Assessment of Effectiveness of National Guidelines for Diagnosis and Management of GDM developed by MoHFW in terms of Knowledge of Nurse Educators

Mean, mean difference, median, standard error of mean difference, standard deviation and ' $\mathrm{t}$ ' value were computed to assess the effectiveness of the National Guidelines for Diagnosis and Management of GDM developed by MoHFW in terms of knowledge of Nurse Educators (Table 3).

The data presented in Table 3, shows that the mean posttest knowledge score (36.1) was significantly higher than the mean pre-test knowledge score (28.6) with the mean difference of 7.5 , indicates gain in knowledge by the participants. The standard deviation of post-test knowledge scores (7.8) was higher than the standard deviation of pretest (6.3), thus indicates the group was more heterogeneous after disseminating the National Guidelines. The computed ' $t$ ' value was 17.06 which was statistically significant at 0.05 level of significance. Thus we reject null hypothesis and accept the research hypothesis, that there was a significant difference between the mean pre - test and post - test knowledge scores of nurse educators regarding national guidelines for diagnosis and management and diagnosis of GDM developed by MoHFW, at 0.05 level of significance.

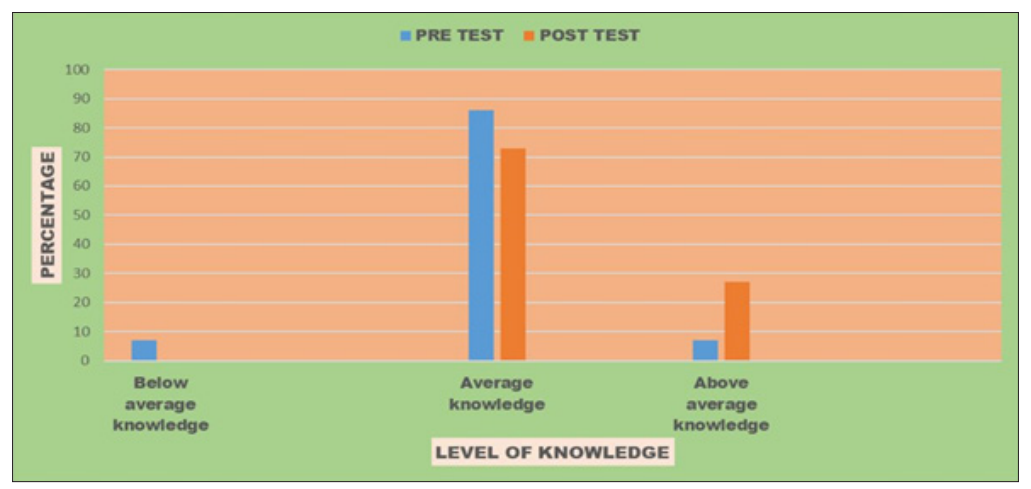

Figure I.A bar diagram showing percentage of knowledge score of nursing educators obtained in pre-test and post-test

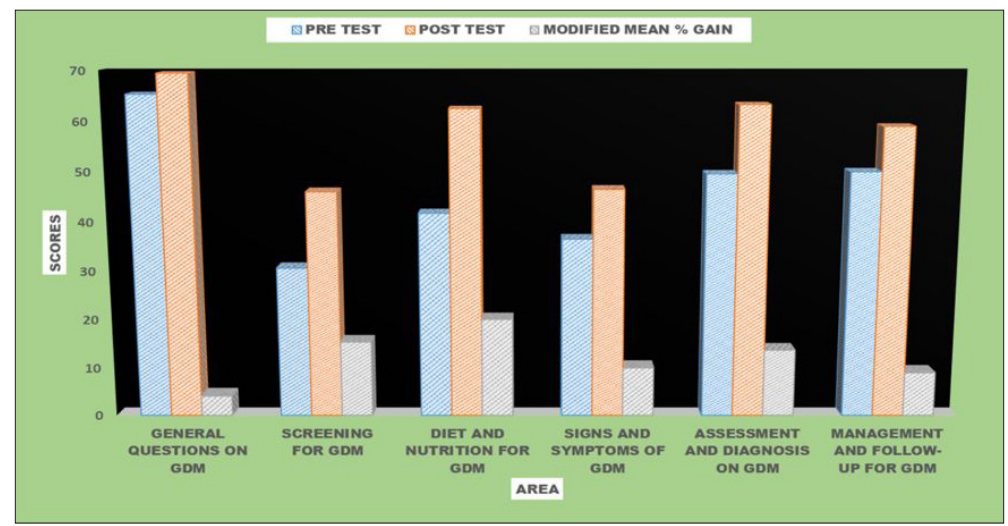

Figure 2.Compound bar diagram showing area-wise modified mean percentage and modified mean percentage gain in post-test knowledge score of nurse educators 
Table 3.Mean, mean difference, median, standard error of mean difference, standard deviation, range and ' $t$ ' value of mean pre-test and post-test knowledge scores of nurse educators

\begin{tabular}{|c|c|c|c|c|c|c|c|c|}
\hline $\begin{array}{c}\text { Knowledge } \\
\text { test }\end{array}$ & $\begin{array}{c}\text { Range of } \\
\text { obtained score }\end{array}$ & Mean & $\begin{array}{c}\text { Mean } \\
\text { difference }\end{array}$ & Median & $\begin{array}{c}\text { Standard Error } \\
\text { of Mean }\end{array}$ & $\begin{array}{l}\text { Standard } \\
\text { Deviation }\end{array}$ & ' $t$ ' & $\begin{array}{c}p \\
\text { value }\end{array}$ \\
\hline Pre-test & $18-43$ & 28.6 & \multirow[b]{2}{*}{7.5} & 27 & \multirow[b]{2}{*}{0.44} & 6.3 & \multirow[b]{2}{*}{17.06} & \multirow[b]{2}{*}{$0.00^{*}$} \\
\hline Post-test & $25-52$ & 36.1 & & 35 & & 7.8 & & \\
\hline
\end{tabular}

$\mathrm{p} \leq 0.05^{* *}$ significance at 0.05 level.

Section 5: Findings related to Association between Post-test Knowledge Scores of Nurse Educators regarding National Guidelines with their selected Demographic Variables

The association between post-test knowledge scores of nurse educators with their professional qualification, designation, years of experience and attended programme on GDM was determined using Fisher's Exact test (Table 4).

The data presented in Table 4, shows that, there was no significant association between the knowledge of nurse educators with their selected demographic variable after administration of National Guidelines.

\section{Discussion}

The present study was aimed to assess the effectiveness of National guidelines for diagnosis and management of GDM developed by MoHFW in terms of knowledge among nurse educators and reassessment of knowledge score after administering the Guidelines.

Table 4.Association of post-test knowledge scores of nurse educators with their selected demographic characteristics

$(n=30)$

\begin{tabular}{|c|c|c|c|c|c|}
\hline \multirow{2}{*}{$\begin{array}{l}\text { S. } \\
\text { No. }\end{array}$} & \multirow[b]{2}{*}{ Demographic characteristics } & \multicolumn{3}{|c|}{ Knowledge score } & \multirow{2}{*}{$\begin{array}{c}\text { p-value } \\
\text { (Fisher's exact test) }\end{array}$} \\
\hline & & $\begin{array}{c}\text { Below } \\
\text { average }\end{array}$ & Average & $\begin{array}{c}\text { Above } \\
\text { average }\end{array}$ & \\
\hline \multirow[t]{4}{*}{1.} & Professional Qualification & & & & \multirow{4}{*}{0.99} \\
\hline & B.Sc. Nursing & 0 & 1 & 0 & \\
\hline & M.Sc. Nursing & 0 & 20 & 7 & \\
\hline & Ph.D. Nursing & 0 & 1 & 1 & \\
\hline \multirow[t]{7}{*}{2.} & Designation & & & & \\
\hline & Clinical instructor & 0 & 0 & 0 & \multirow{6}{*}{0.90} \\
\hline & Tutor & 0 & 14 & 6 & \\
\hline & Senior Tutor & 0 & 1 & 0 & \\
\hline & Lecturer/ Assistant Professor & 0 & 5 & 0 & \\
\hline & Associate Professor & 0 & 1 & 1 & \\
\hline & Professor & 0 & 1 & 1 & \\
\hline \multirow[t]{5}{*}{3.} & Experience in Years & & & & \multirow{5}{*}{0.15} \\
\hline & $1-5$ & 0 & 15 & 1 & \\
\hline & $6-10$ & 0 & 2 & 4 & \\
\hline & $10-15$ & 0 & 3 & 1 & \\
\hline & Above 15 & 0 & 2 & 2 & \\
\hline \multirow[t]{3}{*}{4.} & $\begin{array}{c}\text { Attended Programme } \\
\text { on GDM }\end{array}$ & & & & \\
\hline & Yes & 0 & 3 & 2 & \multirow{2}{*}{0.75} \\
\hline & No & 0 & 19 & 6 & \\
\hline
\end{tabular}

$p>0.05$, hence not significant at 0.05 level of significance. 
In the present study, the data revealed that only $17 \%$ of the nurse educators had attended programme on GDM whereas $83 \%$ of them have not attended any programme on GDM. Similar study was conducted by Nagwa AD, Afefy $\mathrm{FA}^{4}$ related to effect of structured educational session about gestational diabetes on maternity nurse's knowledge at selected primary health care hospitals, Egypt, the result showed that only $13.95 \%$ of nurses attended conference on GDM whereas $86.05 \%$ nurses had not attended any conference on GDM.

The present study also revealed that, before administering the Guidelines to nurse educators only 2 (7\%) had above average knowledge score which was increased to 22 (73\%) in post-test score. Comparison of pre and post-test result was statistically significant as evident from ' $t$ ' value 17.1 $(p=0.00 *)$ indicating the effectiveness of the administration of National Guidelines.

Similar study was conducted by Patel $S$ and Vyas $S^{1}$ to know the profile of Health care providers, their knowledge and management of GDM. Reassessment of knowledge was done after training program. The data revealed that before training 162(40.5\%) participants could correctly tell about GDM which increased to $50 \%$ after the training. Comparison of pre-test and post-test result was statistically significant $\left(p=0.014^{*}\right)$.

\section{Conclusion}

The present study concluded that the nurse educators had below average knowledge regarding National Guidelines for diagnosis and management of GDM developed by MoHFW. The low knowledge scores of nurse educators was because they were either not updated with the recent Guidelines, as only 5 out of 30 had attended any programme on GDM. It was observed that dissemination of guidelines among nurse educators was an effective study material for them and hence for imparting knowledge to nursing students in various colleges of nursing, New Delhi.

\section{Conflict of Interest: None}

\section{References}

1. Patel $S$, Vyas $S$. Evaluation of training program about awareness of Gestational Diabetes Mellitus (GDM) among health care workers of Ahmedabad Municipal Corporation. National Journal of Community Medicine 2018; 9(2): 114-119.

2. Government of India. Maternal and Health Division, National Guidelines for Diagnosis and Management of Gestational Diabetes Mellitus. Ministry of Health \& Family Welfare, New Concept Information Systems, New Delhi, India. 2014.

3. Government of India. Maternal and Health Division, Diagnosis and Management of Gestational Diabetes Mellitus: Technical and Operational Guidelines. Ministry of Health \& Family Welfare, New Concept Information Systems, New Delhi, India. 2018.

4. Nagwa AD, Afefy FA. Effect of structured educational session about Gestational diabetes on maternity nurse's knowledge at selected primary health care hospitals, Egypt. Journal of Education and Practice 2017; 8(17). 